\title{
O USO DOS RECURSOS TECNOLÓGICOS NO ENSINO BILÍNGUE PARA ACADÊMICOS SURDOS
}

Kelly Priscilla Lóddo Cezar ${ }^{1}$ Katherine Fischer ${ }^{2}$

RESUMO: A pesquisa teve como por objetivo compreender como os acadêmicos surdos observam os recursos tecnológicos no ensino bilíngue. Para tanto, optou-se por uma investigação de cunho exploratória com oito acadêmicos surdos que estavam regularmente matriculados no ensino superior e que tivesse concluído alguma disciplina ofertada na modalidade híbrida. A coleta de dados se deu através de entrevistas semiestruturada (escrita e sinalizada em Libras) sobre o uso das tecnologias no ensino superior. Os resultados confirmaram a hipótese inicial da pesquisa e a da literatura especializada em que os surdos se identificam com o uso de plataformas, a definem como interessante e motivadora, porém o docente deve ter domínio para estimular as aprendizagens e as linguagens para não se tornar um depósito de atividades. O conjunto de respostas revelou que: a) os fóruns colocados em primeiro lugar quanto à manifestação formal da escrita do português; b) opinaram criticamente a falta de materiais digitalizados e bilíngues no ensino superior e c) os poucos materiais disponíveis, não utilizados satisfatoriamente pelos docentes. Dessa forma, concluímos que a educação híbrida é um meio eficaz e atraente propício para incorporação dos recursos de acessibilidade visual - vídeos, entre outros, mas ainda é um recurso não explorado em razão da escassez de formação docente.

Palavras-Chave: Libras, Ensino Bilíngue, Educação Híbrida.

\section{THE USE OF TECHNOLOGICAL RESOURCES IN BILINGUAL TEACHING FOR DEAF UNDERGRADUATES}

\footnotetext{
1 Pós-doutora pela Universidade Estadual do Oeste do Paraná (UNIOESTE). Doutora pelo Programa de Linguística e Língua Portuguesa da Universidade Estadual Paulista Júlio de Mesquita Filho (UNESPFClar/Araraquara). Professora Adjunta da Universidade Federal do Paraná (UFPR), campus de Curitiba. Participante do Grupo de pesquisa Formação de professores em línguas estrangeiras (UFPR). E-mail; kellyloddo@ufpr.br

2 Pós-graduanda em Educação Especial com ênfase em Deficiência Auditiva pela Faculdade Educacional da Lapa (FAEL). Pós-graduada em Gestão de Projetos pela Universidade de São Paulo (USP). Graduada em Arquitetura e Urbanismo pela Universidade Positivo (UP). Atualmente, acadêmica do curso do Letras Libras em Licenciatura pela Universidade Federal do Paraná (UFPR). Desde 2018, aluna-pesquisadora do Programa de Iniciação científica e Integração Acadêmica da Universidade Federal do Paraná (UFPR 20182019/2019-2020) vinculada ao projeto de pesquisa Gêneros Textuais e o Ensino para Surdos (BANPESQ/THALES: 20160221902). E-mail: kathe.fischer@gmail.com
} 
ABSTRACT: This research aimed at understanding how Deaf undergraduates perceive the use of technological resources on bilingual teaching. We have chosen thus to conduct an exploratory investigation with eight Deaf undergraduates regularly enrolled in higher education and that had completed at least one hybrid course. The data collection was made through semi-structured interviews, in written Portuguese and Brazilian Sign Language, about technology use in higher education. The results have confirmed our initial hypothesis draw from research on the specialized literature, that the Deaf identify with the use of digital platforms, finding it interesting and motivational, but the educator must dominate these resources in order to stimulate learning and language, and not to become an activities storehouse. The responses have shown that (a) the forums were rated highest as formal Portuguese writing; (b) the students have criticized the lack of digital and bilingual materials in higher education; and (c) the few existing materials are not adequately used by teachers. Hence we conclude that hybrid education is an efficient and interesting strategy, suitable for embedding visual accessibility tools (like videos). Yet it still is underexploited due to the lack teacher training on it.

Keywords: Brazilian Sign Language; Bilingual; Hybrid education.

\section{INTRODUÇÃO}

O ingresso no ensino superior é um desafio para qualquer estudante independentemente da sua cor, raça, condição financeira ou mesmo de idade, todos os estudantes quando adentram a universidade necessitam de alterações nas suas vidas (pessoal, profissional, familiar), pois dependendo de suas adequações e de suas disponibilidades possam aproveitar, ou não, as oportunidades oferecidas pela universidade (pesquisa, ensino e extensão). Seguindo essa linha de pensamento, os pesquisadores Sampaio e Santos (2002) são mais enfáticos aos salientarem que quando os estudantes sofrem os problemas de transição e de adaptação nesta fase são suscetíveis ao fracasso escolar que acaba por gerar o abandono. Tal sofrimento é compreendido como dificuldades de incorporar os novos conhecimentos, sendo necessário retomar as falhas de aprendizagem da trajetória escolar como os problemas de compreensão em leitura e de interpretação; dificuldade de produção de textos; deficiências de linguagem; inadequação das condições de estudo, falta de habilidades lógicas, entre outros.

Quando nos reportamos aos acadêmicos surdos, essas lacunas são mais intensas, uma vez que além da comunidade academia não estar preparada para perspectiva bilíngue para surdos poucos materiais e docentes são fluentes ou 
conhecem a Língua Brasileira de Sinais - Libras, no Brasil. No entanto, assim como qualquer outro acadêmico, terão que se adaptar com a nova realidade, enfrentando as expectativas, as normas e os modos de funcionamento diferentes daqueles de sua experiência escolar anterior. Assim dependerá de sua história, de suas características e de suas habilidades pessoais, de seu esforço para encarar o período de desenvolvimento próprio da faixa etária do jovem adulto, marcado pela construção de identidade, da autonomia, de ideais e de relações interpessoais (FERREIRA; ALMEIDA; SOARES, 2001).

No Brasil, há um aumento de acadêmicos surdos - cerca de 5.404 deficientes auditivos e cerca de 2.138 surdos - matriculados em instituições públicas e privadas (BRASIL/MEC, 2018). Tal crescente se deve ao reconhecimento da Língua Brasileira de Sinais em âmbito nacional (Lei no 10.436/2002), no entanto a dizimação do conhecimento desta língua sinalizada deve-se efetivamente ao Decreto no 5.626/2005 que incorporou a disciplina de Libras como obrigatória, em especial, em cursos de licenciatura e de fonoaudiologia, entre outras legislações que estimulou a comunidade surda a ocuparem espaços sociais jamais ocupados em razão do retrocesso histórico causado pelo Congresso de Milão (1880-1980). Assim, com a participação ativa de pessoas com deficiência em diferentes contextos sociais, fizeram as universidades perceber a necessidade de oferecer acessibilidade aos surdos e outras pessoas com deficiência.

Em conformidade com a literatura especializada (AMORIM; SOUZA; GOMES, 2016), as novas tecnologias é uma grande aliada à acessibilidade linguística aos surdos, uma vez que os suportes tecnológicos, vídeos, Youtube, WhatsApp, plataformas educacionais maximizam a comunicação articulando diferentes linguagens (desenho, vídeo, ícones, escrita, sinalização) indo ao encontro perspectiva bilíngue de aprendizado efetivo para surdos. A partir dessas considerações, somadas as nossas experientes docentes, esta investigação teve por compreender como os acadêmicos surdos observam os recursos tecnológicos no ensino bilíngue. 


\section{PRESSUPOSTOS TEÓRICOS}

Os princípios da educação a distância, EAD, surgem como ferramenta estratégica importante de sobrevivência pessoal e profissional, como consequência da globalização, de aumento assustador de níveis de concorrência, e do agravamento da desigualdade social no país (OLIVEIRA, 2007). Saber utilizar essas ferramentas, em especial, as mais essenciais, também pode se tornar uma forma de emancipação e de formação para os alunos surdos, uma vez que o principal meio de divulgação da Libras são os vídeos e as redes sociais.

Na EAD, as ferramentas utilizadas para sua atualização vão desde o material impresso até a internet passando pela televisão, rádio, fitas de vídeo e áudio, CD-ROM, orientação por computador, videoconferências, teleconferências, correio eletrônico, fórum, chat, orientações presenciais e por correspondência, proporcionando assim ao aluno uma oportunidade de atualização sem afastamento de suas atividades.

Tal adaptação se faz e fez necessárias em razão de que a sociedade atual requer um novo educador, exige do docente não mais uma transmissão de conhecimento, mas um docente multiplicador de conhecimento, que dê conta de linguagens diversificadas. Mais do que aprender a fazer, ele deve ser formado para aprender a aprender, como é o caso da Libras ocupando os espaços acadêmicos no Brasil.

Nesse sentido, para quem trabalha no ensino superior, foco de investigação deste trabalho, torna-se cada vez mais necessário os conhecimentos e uso das NTIC (Novas Tecnologias de Informação e Comunicação) para melhorar a eficiência e eficácia do ensino-aprendizagem e assim a atuação e crescimento profissional dos docentes. O ideal seria a utilização plena dos recursos da $E A D$, entretanto encontramos desafios para desenvolvê-la. Entre esses desafios, destacamos: a) dificuldade de acesso às tecnologias da comunicação e informação por parte de alguns profissionais de saúde; b) dificuldade em utilizar as ferramentas; c) escassez de tempo para desenvolver as atividades do curso em vista do duplo emprego; d) dificuldade de comunicação com os tutores por morarem em locais muito distantes; e) a questão da família, entre outros (OLIVEIRA, 2007). 
A partir dessa perspectiva, observamos que esse novo agir na educação poderá levar os alunos surdos a desenvolverem a escrita acadêmica para elaboração dos principais gêneros acadêmicos que circulam no contexto universitário (resumo, resenha, artigo científico), ainda de forma prioritária na modalidade escrita e não sinalizada como deveria ser o ideal. No entanto, a partir dos princípios da competência continuada, através da cooperação, participação, responsabilidade e autoaprendizagem, melhorando assim sua dinâmica de ensino os recursos tecnológicos têm se demostrado eficaz nesta área do saber. Os dados referentes às pesquisas anteriores envolvendo graduandos surdos no em aulas de pós-graduação (CEZAR, 2012), demostram que os fóruns de aprendizagem se constituem em uma ferramenta indispensável e benéfica para o aprendizado da escrita, no entanto no contexto educacional - formação de professores, é indiscutível a importância da interação para o desenvolvimento da aprendizagem significativa. No ambiente virtual, esse processo de interação é tão importante como na modalidade presencial, visto que esse processo se dá como uma ação de reciprocidade entre pessoas que pode ser direta ou indireta.

Seguindo esta esteira de pensamento, Lévy (1998) e Santos (2006) assinalam que na $E A D$, a interação plena dessa relação se organiza nos fóruns, ferramenta essa que tem como principal função estabelecer relação entre aluno-professor e alunoaluno, sendo a principal função discutir os conteúdos expostos nas aulas gravadas, materiais disponibilizados e web conferências. Assim como qualquer ferramenta educacional, o fórum por si não promove a interação, ela depende da efetividade dos professores e dos alunos entrados no alcance do conhecimento. Isso quer dizer que, essa ferramenta auxilia no processo de ensino aprendizagem. Cabe destacar que, o fórum é uma ferramenta que promove o diálogo entre os alunos, proporciona troca de experiências educacionais e o debate de ideias. Como consequência, promove a construção de novos saberes. Na sua dinâmica, permite a conversa de todos com todos, cada qual ao seu tempo, possibilitando a criação de um ambiente centrado na interação online. 
Santos (2006, p. 229), ao tratar das ferramentas disponibilizadas pelos ambientes virtuais, salienta que o fórum é "uma interface na qual emissão e recepção se ligam e se confundem de modo a permitir que uma mensagem seja comentada por todos os participantes alimentando a inteligência coletiva através da colaboração todos-todos".

Ainda seguindo esse tema, Lévy (1998) assevera que a inteligência coletiva é fruto de uma soma de interações individuais que ao entrarem em contato com outros tornam um conjunto de pensamentos. Nesse sentido, cita o fórum de discussão como um espaço privilegiado para interação, já que esse suporte permite intensas discussões e reflexões motivando a construção do conhecimento em conjunto e explícito.

É nesse contexto de interação promovido pela interação com os recursos tecnológicos que investigação busca compreender por parte dos acadêmicos surdos suas experiências com a modalidade híbrida de ensino destacando a positividade e a negatividade a fim de promover e identificar as partes frágeis que necessitam ser fortificadas, em especial, a relação com a escrita formal da Língua Portuguesa.

Para tanto, utilizamos os resultados das pesquisas anteriores de Cezar (2012) como norte para escolha tanto do encaminhamento teórico como metodológico aqui apresentado. A escolha pela língua sinalizada e pelos gêneros digitais se dá na confluência de os gêneros digitais serem mais visuais e atender as características linguísticas das línguas sinalizadas que também é visual.

A partir destes dados, observamos que o crescimento e a difusão do uso das tecnologias aumentam a cada instante acabando por funcionarem como um processo de ampliação de interações sociais (DELMAR; ARCOVERDE, 2006). Ao relacionarmos para área educacional, observa-se que as tecnologias digitais, se fundamentadas, podem se transformar em uma excelente ferramenta metodológica para os aprendizes.

Quando relacionado com a área da Educação a Distância $(E A D)^{3}$ salientamos ser uma das mais importantes ferramentas de difusão do conhecimento e de

\footnotetext{
${ }^{3}$ Um dado importante de ser mencionado é portaria $\mathrm{n}^{\circ} 1.428$, de 28 de dezembro de 2018 , em que o Ministério da Educação aumentou a carga horária de aulas a distância em cursos presenciais do ensino superior de $20 \%$ para $40 \%$.
} 
democratização da informação, cumprindo bem seu papel de educar, reduzir as dificuldades impostas pelas distâncias, facilitar a vida do aluno e disseminar o ensino aos cantos mais remotos do planeta, sendo uma iniciativa válida e que deve ser experimentada (HANSEN, 2003).

Ancoradas nas considerações de Kenski (2001), que tem destacado os recursos de rede nas formas híbridas de ensino evidenciando um novo meio de interação e gerando novas formas de estudos e trabalho articulamos com os estudos do bilinguismo para surdos, uma vez que a língua escrita, para os acadêmicos sinalizantes, trata-se de ser a sua segunda língua, tanto a leitura quanto a escrita acabam sendo motivo de preocupação e em grande parte de limitação, quando não se tem o bilinguismo para surdos como didática no ensino (KUBASKI; MORAES, 2009).

Seguindo a discussão na linha dos gêneros discursivos/textuais, em especial, os digitais, e articulando com a temática da presente pesquisa, observamos que com o surgimento das novas tecnologias de informação e comunicação, os novos gêneros nascem e outros são modificados. Os gêneros que se apresentam no ambiente virtual são chamados gêneros virtuais ou digitais, ou seja, "a internet transmuta de maneira bastante complexa gêneros existentes, desenvolve alguns realmente novos e mescla vários outros" (MARCUSCHI, 2004, p.18).

De acordo com as colocações do linguista, observamos que os gêneros digitais possuem características peculiares devido ao ambiente dinâmico e interativo em que se circulam, como: a hipertextualidade, a linguagem multimodal e o hibridismo. Esses fenômenos acabam por desenvolver relações interpessoais, como também modificam a linguagem utilizada, com o uso de abreviaturas e emotions. Alguns exemplos de gêneros digitais são: E-mail, Facebook, Youtube, Plataforma Educacional - Moodle e entre outros. Neste caso, particular, você utiliza um emotiom no lugar de uma frase, de uma oração e em alguns casos até de um texto.

Nos ambientes digitais, em função da rapidez da comunicação, damos preferência a escrita de uma forma abreviada, utilizamos sentenças mais curtas e fazemos uso de hipermídias e links que acabam por construir um hipertexto. As mensagens acabam sendo mais curtas. No entanto, cabe destacar que não se trata de 
uma linguagem mais simples do que a escrita formal. Refere-se a maioria de uso. Cabe destacar que mesmo na internet temos gêneros digitais de cunho formal. O suporte e a quem se destina a informação que irá determinar o índice de formalidade, como é o caso da presente investigação, em razão de ter como foco os acadêmicos surdos.

Observamos que os benefícios da TIC são imensos quando o processo de intervenção e preocupação com o ensino se dá de uma forma clara, objetiva e atendendo as características da EAD. Os gêneros digitais promovem um processo de tomada de consciência das ações pelo suporte em que circula e pela forma como o professor conduz. Ela permite um descentramento do saber único do professor, visto que a própria estrutura do gênero digital, quando compreendida facilita a compreensão do aluno.

Além disso, as divulgações de materiais das produções se tornam de mais fácil acesso, fazendo com que as informações acabem por chegar mais rápido, mesmo utilizando a formalidade da língua e levando a Libras como primeira língua com mais facilidade articulando links e hiperlinks acessíveis disponíveis na internet. Dessa forma, o bilinguismo para surdos acadêmicos fica mais próxima das necessidades linguísticas educacionais para comunidade. No entanto, utilizar a EAD e a educação Híbrida não é uma tarefa fácil e tranquila como costumam vulgarizar, uma vez que o profissional (mediador-professor) necessita ter mais qualificação e perfil na área da comunicação visual.

\section{MATERIAIS E MÉTODOS}

Para atender ao objetivo proposto na presente investigação - compreender como os acadêmicos surdos observam os recursos tecnológicos no ensino bilíngue -, optou-se por uma investigação de cunho exploratória (TRIVIÑOS, 1987), com abordagem descritiva explicativa com oito acadêmicos surdos que estavam regularmente matriculados no ensino superior da capital de Curitiba/PR. Aos participantes foi realizado um convite de participação voluntária seguindo as diretrizes do comitê de ética em pesquisa com seres humanos ${ }^{4}$ (CEPE). Além desse critério

\footnotetext{
- ${ }^{4}$ Resoluções 466/12-510/16
} 
(aceitar voluntariamente a participar) teria de ter concluído alguma disciplina ofertada na modalidade híbrida na plataforma Moodle. A escolha da plataforma investigada se deve por ser a implementada no ensino superior público nacional também utilizada em instituições superiores particulares, ou seja, gratuita e amplamente conhecida.

A pesquisa foi dividida em três grandes momentos: 1) pesquisa bibliográfica; 2) pesquisa exploratória; 3) categorização, transcrição (Libras para o português escrito) e análise dos dados.

A revisão bibliográfica, primeira etapa, baseou-se em livros, artigos científicos, monografias, dissertações, teses e sites de pesquisas. Junto a isso, a fim de verificar a originalidade do trabalho, bem como os materiais produzidos na área acadêmica mais atuais, tornou-se importante realizar o levantamento de teses, dissertações e periódicos em bases indexadas. O resultado dessa etapa identificou quatro investigações envolvendo o presente tema, no entanto quando articulado com a presente proposta se mostrou inexistente (Libras, tecnologias, ensino híbrido, acadêmicos surdos). Esses resultados evidenciam originalidade na pesquisa proposta.

Na sequência, a coleta de dados se deu através de entrevistas semiestruturada (escrita e sinalizada em Libras) contendo cinco questões norteadoras sobre o uso das tecnologias no ensino superior, sendo: 1) Como você avalia a sua utilização de recursos tecnológicos, incluindo a plataforma Moodle, no ensino superior? 2) Quais foram suas dificuldades ao utilizar os recursos tecnológicos e a plataforma Moodle? 3) Você acredita que os recursos tecnológicos e a plataforma Moodle contribuem para o aprendizado e uma melhoria na escrita da Língua Portuguesa? Por quê? 4) Na sua opinião, como seus professores estão com os recursos tecnológicos? Estão atualizados e adaptados? Utilizam os fóruns para a integração? A coleta de dados foi realizada durante os meses de junho e julho de 2019 e teve uma duração média de 20 minutos.

Por fim, a partir das entrevistas semiestruturadas organizamos a as repostas em categorias conceituais para evitar repetições e focalizarmos nos temas da investigação. Cabe salientar que a pesquisadora que coletou os dados é surda e como os participantes são surdos a coleta ocorreu tendo a Libras como primeira língua e as questões norteadoras também foram disponibilizadas por escrito - Português (L2) 
atendendo os preceitos do bilinguismo. Os participantes foram devidamente mantidos em sigilo e aqui foram nomeados aleatoriamente como P1, P2, P3, P4, P5, P6, P7 e P8, significando $\mathrm{P}=$ Participante da pesquisa e a marcação numérica seguindo a ordem em que as entrevistas aconteceram. Como os participantes não tiveram contato um com os outros e nem com o dia e horário do outro a marcação numérica foi escolhida pelas pesquisadoras.

Dessa forma, analisamos o conjunto de respostas para compreender o uso dos recursos e a acessibilidade no meio digital, da forma como possam influenciar o ensino e a aprendizagem dos surdos acadêmicos na Língua Brasileira de Sinais (L1) e na Língua Portuguesa (L2) podendo os resultados aqui apresentados torna-se mais um dado e recurso disponível nesta área de investigação.

\section{APRESENTAÇÃO E DISCUSSÃO DOS RESULTADOS}

O crescimento e a difusão do uso das tecnologias aumentam a cada instante acabando por funcionarem como um processo de ampliação de interações sociais (DELMAR; ARCOVERDE, 2006). Ao relacionarmos para área educacional, observa-se que as tecnologias digitais, se fundamentadas, podem se transformar em uma excelente ferramenta metodológica para os aprendizes. No entanto, não é tão simples como parece. Como a área das novas tecnologias estão em constante mudança e aperfeiçoamento, necessita do profissional também atualizado. De acordo com o estudioso Nogueira $(2014 ; 2015)$, os professores têm de estar abertos e em constante aperfeiçoamento para que quando necessário precisamos mudar e enfrentar as novas mudanças que acabam por gerar novos desafio, como é o caso da acessibilidade linguística para surdos. Já que, em conformidade com a literatura especializada, aplicar as novas tecnologias na área educacional requer muito envolvimento, agora imaginem na área de inclusão.

A partir dessas considerações teóricas, somadas as nossas inquietações, apresentemos neste momento os resultados obtidos na presente investigação sob o olhar dos acadêmicos surdos. Como salientado na metodologia, as quatro perguntas semiestruturadas foram categorizadas conceitualmente levando em conta as 
similaridades das respostas obtidas. Quanto as respostas sobre: Como você avalia a sua utilização de recursos tecnológicos, incluindo a plataforma Moodle, no ensino superior? Destacamos as seguintes respostas:

P2: Algumas matérias poderiam melhorar para ter mais dinâmica, com a participação dos professores respondendo as dúvidas, explorar mais as ferramentas para ter mais os conteúdos.

P3: Moodle ajuda pouco pois falta orientação como estudar Moodle sabe. Só postar vídeo link ou texto, falta professor elaborar dos alunos. Uso mais estudo Google. Facebook muito difícil. Youtube depende vídeo tema professor pede ou se tiver tradução texto para vídeo Youtube.

P7: Como acadêmico, eu uso recursos tecnológicos sim, mas a plataforma Moodle da própria universidade, não uso muito. Porque não tenho interesse e uso só para baixar material e ver os feedbacks. Quando eu pergunto para tirar dúvida, o professor demora muito para responder. Por isso o Moodle não é muito utilizado $e$ interessante. Eu sempre uso o Google como recurso tecnológico para estudo bilíngue. Facebook, de vez em quando. Youtube, uso sim, quando tem alguma coisa em Libras para assistir, de vez em quando tem informações. Como os artigos, pesquisas... tem vídeos do Youtube em Libras e com legendas, que ajudam a ensinar como fazer, assim eu aprendo sim.

Pelas respostas destacadas, da primeira questão sobre a utilização de recursos tecnológicos pelos alunos no ensino superior, notou-se que todos os entrevistados (8/100\%) não utilizam a plataforma Moodle por falta de interesse e de acessibilidade. Para os entrevistados, outros meios digitais são mais interativos e atendem com mais eficácia a questão da visualidade e de suporte com vídeos sinalizados, como por exemplo, os recursos do Google ou até mesmo o Youtube. Essas considerações vão ao encontro da literatura especializada (GOETTERT, 2014; 2019; FLOR; VANZIN, 2019), que salientam a importância desses meios apresentarem acessibilidade em diferentes áreas, no caso específico de usuários de língua de sinais, os recursos como suporte de vídeo, telas interativas, janela com intérprete, são imprescindíveis para o acesso e a manutenção dos usuários dentro do contexto educacional digital. 
Essas dificuldades são complementadas com o segundo conjunto de respostas: Quais foram suas dificuldades ao utilizar os recursos tecnológicos e a plataforma Moodle? conforme evidencia-se as destacadas a seguir:

P1: No meu caso não tive dificuldades por saber procurar e encontrar o que eu precisava. Porém o académico geral, se ele não tiver uma estrutura antes, as maiores dificuldades seriam entender o momento que é fórum, e o momento que é atividades. A linquaqem precisaria ser mais simples, fácil e dinâmico.

P6: Não tive muitas dificuldades ao utilizar, pois já tive experiências com os recursos tecnológicos $e$ as plataformas antes. Com a plataforma Moodle, eu tive um pouco, ou seja, 10\%, pois essa plataforma usa a Línqua Portuquesa (L2). O principal problema foi no fórum de discussão, pois estava muito confuso e muitos não sabiam onde postar nem como escrever. Sem acessibilidade digital e sem manual para acesso. Quanto aos professores, alquns professores utilizavam a linguagem muito formal na escrita, os alunos surdos não conseguiam entender. Também não tinha integração entre alunos $e$ professores e o problema era a demora de respostas dos professores na plataforma para dúvidas e feedbacks.

As respostas nos encaminham para seguinte compreensão, somente dois dos usuários (P1 e P6) salientaram que não encontraram dificuldades em utilizar. Tias respostas nos faz supor que esses participantes têm experiências anteriores com a modalidade a distância e realizaram cursos utilizando esta plataforma educacional. Já no outro conjunto de respostas, identificamos o uso da plataforma Moodle como tendo um índice de dificuldade razoável, conforme a resposta a seguir:

P8 (repetição da resposta 1): Se tiver mais conhecimento sobre a saber de uso o Moodle, vai ajudar a bastante para acadêmicos a usar com facilidade de acesso o Moodle, e para mim é razoável de uso Moodle, e sobre redes sociais, sim uso bastante até mesmo o Google para os estudos acadêmicos mesmo. Principalmente, Google acadêmico que é específico na área de artigos, até mesmo tese para fazer as pesquisas.

Em consonância com nossas percepções, observa-se que mesmo o participante tendo colocado como que o incide venha a ser razoável, acaba por salientar que há necessidade de saber anteriormente P8 "Se tiver mais conhecimento sobre a saber de 
uso o Moodle" faz uma relação direta com o uso de redes sociais. Ainda envolvendo esta questão, no terceiro conjunto de resposta, categorizamos como a maioria dos participantes (5 - 62\%) em afirmarem que apresentam dificuldades em manusear a plataforma e as principais justificativas foram: a) falta de tradução em Libras dos materiais e b) falta de suporte no decorrer da disciplina - prática e conceitual.

P2: Sendo aluna surda, encontro poucos textos repassados nos arquivos e não tem a tradução de Libras para compreender melhor.

P7: Eu tenho dificuldades e barreiras sim, dependendo do que tem nos recursos tecnológicos e a plataforma Moodle. Por exemplo, quando eu pesquiso na internet, lendo os textos e consigo entender, mas minha barreira é se expressar e escrever o português. Outro exemplo, o dicionário virtual, a palavra manifestação, eu leio $e$ entendo o significado com dois sentidos diferentes. Mas com a frase formal e tudo, eu não consigo entender nem o contexto, por isso tenho barreira no portuquês. Eu sempre tenho dúvidas e sempre pergunto para minha família, minha mãe, etc.

Em conformidade com as respostas obtidas e a categorização realizada, para interpretação dos dados, recorremos aos estudos de Fernandes e Moreira (2017) que há anos vem discutindo e evidenciando a importância do letramento para surdos acadêmicos, uma vez que estamos no âmbito de uma discussão linguística e política sobre a falta de acesso real de inclusão para aprendizes surdos, com dificuldades na leitura e escrita do português e experiências pouco significativas em língua de sinais.

Refletindo sobre as respostas obtidas, tornou-se relevante destacar que é algo evidente que quase todos possuem suas barreiras com a Língua Portuguesa (L2) que é muito utilizada na plataforma Moodle, uma vez que todos (8-100\%) responderam ter dificuldades com a modalidade formal escrita do português, quando entrevistados sobre: Você acredita que os recursos tecnológicos e a plataforma Moodle contribuem para o aprendizado e uma melhoria na escrita da Língua Portuguesa? Por quê? conforme demostra-se as respostas a seguir:

P2: Depende da aluna surda, teremos que pensar nas dificuldades delas, a maioria não dominam a Língua Portuguesa e apresentam a dificuldade de compreender o contexto do conteúdo. Quanto mais 
vídeos sinalizantes e legendados para que os surdos acompanhem a leituras fará que aumentem o seu vocabulário.

P6: Não acredito, pois, muitos alunos surdos só sabem copiar os textos, usando os recursos tecnológicos como fosse automático, ou seja, não consequem se expressar na escrita. Muitos recursos tecnológicos não possuem acessibilidade nem bilíngues, como os alunos surdos vão aprender e melhorar na escrita da L2?

P7: Sim, acredito. Na verdade, a tecnologia me ajuda a aprender muito e me desenvolver sim, por que a tecnologia significa passar as informações. Mas não são todos os recursos tecnolóqicos que ajudam, pois são ruins como acesso, falta de acessibilidade, etc. Por exemplo, Youtube em Libras ajuda o aprendizado, pois assim o surdo consegue se desenvolver, ter mais informações do mundo e ter mais domínio na L2. Acredito, assim o surdo consegue ter um bom futuro.

A partir das respostas obtidas, observamos que todos os investigados (8-100\%) salientam a importância de se aprender e de ter a escrita do português como forma de expressão e de aprendizado, no entanto destacam que as dificuldades são advindas da formação e da relação que estiveram com o português durante todo o processo de escolarização e as políticas públicas não enfatizam tal questão, dão prioridade para a perspectiva clínica da surdez, como é o caso do Atendimento Educacional Especializado (FERNANDES, 2003).

Além disso, salientaram que o uso nas tecnologias motiva e auxilia o uso da modalidade da escrita, uma vez que passam boa parte do tempo na internet, no entanto destacam que quando se trata de meios formais - educacionais, a exigência da escrita formal da Língua Portuguesa acaba sendo uma espécie de entrave e de resistência de participação na escrita. Esses dados vão ao encontro dos resultados de pesquisas anteriores (CEZAR, 2014) que assevera que a dificuldade da escrita formal por parte de alunos surdos e ouvintes deve-se a falta do que venha a ser escrita sem imposição - tal como vinculada unicamente a regras e acertos e erros, chamada pela a autora de "cultura do erro", em que as metodologias do ensino de Língua Portuguesa devem ser revistos, em especial, dar destaque ao uso dos gêneros textuais, em nosso caso específico - gêneros digitais, e ao processo de escrita e reescrita a partir da estrutura composicional e da função dos gêneros ensinados (CEZAR, 2015). 
Para finalizar a entrevista, perguntamos sobre a opinião de cada um a fim de ver como os professores estão com os recursos tecnológicos, se estão atualizados e adaptados, além dos fóruns para a integração: Na sua opinião, como seus professores estão com os recursos tecnológicos? Estão atualizados e adaptados? Utilizam os fóruns para a integração?

Em razão de ser uma pergunta mais direcionada a opiniões e percepções, a partir do conjunto de respostas, que em boa parte ficou repetitiva como uma junção de todas as perguntas anteriores, destacamos nas respostas obtidas o uso da ferramenta fórum de discussão, uma vez que vai ao encontro do objetivo geral da pesquisa - uso das tecnologias e a relação com a escrita da Língua Portuguesa.

No que tange ao processo de formação e uso dos recursos tecnológicos dos professores, assim como nas respostas anteriores, o conjunto de respostas revelam o baixo desempenho e uso das tecnologias na visão dos aprendizes investigados, conforme evidencia as respostas abaixo:

P1: Infelizmente não. Na questão de entender os recursos até eles se perquntam como faz. Sobre a utilização dos fóruns, eles mandam como obrigatório e não tem interação deseja e sim como obrigatória apenas. Que os professores têm que usar melhores jeito que interagir em fórum, e procurar explorar mais o Moodle que deve ser uma ferramenta complexa. Mas a complexidade é boa e facilita a vida dos dois lados.

P3: Minha experiência atual alguns professores não elaborar nada só observação se fez atividades ou não. Alguns elaborar para guiar caminho estudo das atividades. Depende professor adaptação com alunos também. Sistemas Moodle não atualiza, continua mesmo forma de limitado escrita ou vídeo. Como esse sistema padrão bem antigo mais limite regras jeito distância.

P8: Bom, só única docente que usa mais Moodle, tem adaptado em Libras e infelizmente a maioria não usa o Moodle já que parece é um complexo para eles e até mesmo alunos.

Um dado que nos chama atenção, refere-se a uso do fórum como forma de interação e de aprendizado por arte dos alunos e consequentemente relacionando ao processo de interação aluno-professor-escrita formal. Este recurso é um dos mais 
utilizados na plataforma Moodle, pode ou não ser avaliativo é definido pelos estudiosos como uma ferramenta que permite discussões on-line por meio de mensagens assíncronas (ao longo dos dias, semanas, meses ou duração do curso).

É um espaço importante para troca de ideias, de opiniões, de informações e, até mesmo, de sentimentos em relação aos assuntos propostos. A participação dos vários atores no fórum enriquece o debate e ajuda a elaborar melhor o assunto. Espaço para discussões mais elaboradas (LÉVY, 1998; 2011; SANTOS, 2006).

\section{CONSIDERAÇÕES FINAIS}

A pesquisa sobre os recursos tecnológicos utilizados no ensino bilíngue para acadêmicos surdos teve como objetivo abordar esse uso e a acessibilidade no meio digital, a forma como influenciam o ensino e a aprendizagem dos surdos na Língua Brasileira de Sinais (L1) e na Língua Portuguesa (L2).

Através dessa pesquisa, verificou-se a disponibilização de recursos tecnológicos no ensino superior como a plataforma Moodle, oferecendo uma nova demanda aos professores a respeito da integração desses recursos com os acadêmicos surdos no processo de ensino e aprendizagem.

Quanto à integração, não significa que apenas o professor deve usar algum recurso durante a aula, porém ter o domínio para estimular os alunos e estar diretamente comprometido no processo com os conhecimentos necessários para a utilização da tecnologia de forma integrada e contextualizada, tendo como foco o conteúdo das disciplinas estudadas. As ferramentas na plataforma Moodle auxiliam no processo de aprendizagem do aluno. No entanto, o conteúdo planejado com qualidade é que faz uma aula interessante e que possibilita a aquisição do conhecimento.

As universidades, em especial, as públicas que utilizam essa plataforma em diferentes modalidades de ensino (híbrida, técnica, licenciatura, entre outras) devem oferecer os meios e as oportunidades aos surdos no uso desses recursos tecnológicos bilíngues para obter novos conhecimentos. Além disso, as plataformas Moodle devem ser incorporadas ao cotidiano das aulas trazendo desafios na medida em que favorecem o desenvolvimento de novas situações acadêmicas, ampliando o acesso à 
informação, à participação, à ampliação de redes para o processo de ensino e de aprendizagem. Assim os acadêmicos surdos podem ser mais confiantes e capazes de utilizar tanto a Língua Brasileira de Sinais (L1) como a Língua Portuguesa (L2) na sua comunicação, em diferentes espaços, garantindo acessibilidade na aprendizagem, no ensino e colaborando na formação dos surdos bilíngues.

Os dados apresentados, embora possam ser considerados uma amostra pequena de pesquisa, podem ser melhor aprofundados, como também servirem de estímulo sobre o uso da plataforma Moodle na área de acessibilidade linguística, em especial, quando envolve línguas de sinais - Língua Brasileira de Sinais. No entanto, cabe destacar que, a pesquisa foi iniciada e finalizada entre 2018-2019 e os dados finais foram ao encontro dos resultados divulgados pela literatura especializada na organização de Corrêa e Cruz (2019), envolvendo os maiores pesquisadores nas áreas aqui discutida (tecnologias e educação bilíngue). Tal fator, demostra o crescimento na área de investigação e a necessidade de se discutir os recursos tecnológicos para comunidade surda brasileira.

\section{REFERÊNCIAS}

AMORIM, M. L. C.; SOUZA, F. D. F.; GOMES, A. S. Educação a distância para surdos: acessibilidade de plataformas virtuais de aprendizagem. Appris Editora e Livraria EireliME. 2016.

BRASIL. Decreto-lei no 5.626, de 22 de dezembro de 2005. Diário Oficial [da] República Federativa do Brasil, Brasília, 23 de dez. 2005. Seção 1, p. 30.

BRASIL. Lei no 10.436, de 24 de abril de 2002. Diário Oficial [da] República Federativa do Brasil, Brasília, 25 de abril de 2002. Disponível em: <http://www.feneis.org.br/legislacao/Libras/Lei\%2010.436.htm>. Acesso em: 10 mar. de 2007.

BRASIL, MEC. Ministério da Educação. Censo da Educação Superior 2017. Divulgação dos principais resultados. 2018.2 Disponível em: http://portal.mec.gov.br/docman/setembro-2018-pdf/97041-apresentac-a-o-censosuperior-u-ltimo/file. Acesso em: 10 de março.

BRASIL, MEC. Ministério da Educação. Secretaria de Educação a Distância. Referenciais de Qualidade para Educação Superior a Distância. 2007. Disponível em: 
http://portal.mec.gov.br/seed/arquivos/pdf/legislacao/refead1.pdf. Acesso em: 1 de agosto.

CEZAR, K. P. L. Melhorando a escrita de alunos surdos utilizando fóruns de aprendizagem. In: LEITE, C.; ZABALZA, M. (Org.). Ensino Superior: Inovação e qualidade na docência. 1ed. Porto: CIIE. Centro de Investigação, 2012, v. 1, p. 2082-2099.

CEZAR, K. P. L. Uma proposta linguística para o ensino da escrita formal para surdos brasileiros e portugueses. Tese (Doutorado). Universidade Estadual Paulista Julio de Mesquita Filho. São Paulo, 2014.

CEZAR, K. P. L. Escrita: uma proposta linguística de ensino para Educação Bilíngue dos surdos. Relatório de pós-doutorado. Universidade Estadual do Oeste do Paraná. Foz do Iguaçu, 2015.

DELMAR, R.; ARCOVERDE, L. Tecnologias digitais: novo espaço interativo na produção escrita dos surdos. Cad. Cedes, v. 26, n. 69, p. 251-267, 2006.

FERNANDES, S. Educação Bilíngue para Surdos: identidades, diferenças, contradições e mistérios. Tese de Doutorado. Universidade Federal do Paraná, 2003.

FERNANDES, S; MOREIRA, L. C. Políticas de Educação Bilíngue para estudantes surdos: contribuições ao letramento acadêmico no ensino superior. Educar em Revista, v1. no2, 2017, p. 24-58.

FERREIRA, J. A.; ALMEIDA, L. S.; SOARES, A. P. C. Adaptação acadêmica em estudante do 10 ano: diferenças de gênero, situação de estudante e curso. PsicoUSF, Itatiba, v.6, n.1, p.1-10, jan. 2001.

FLOR, C. S; VANZIN, T. Construção de ambientes virtuais de ensino e aprendizagem acessíveis para surdos: recomendações de projeto e avaliação de usabilidade In: CORRÊA, Y; CRUZ, C.R (Orgs.) Língua Brasileira de Sinais e tecnologias digitais. Porto Alegre: Penso, 2019, p. 27-42.

GOETTERT, N. Tecnologias digitais e estratégias comunicacionais de surdos: da vitalidade da língua de sinais à necessidade da língua escrita. Dissertação (Mestrado). Programa de Pós-graduação em Educação. Universidade do Vale do Rio dos Sinos. São Leopoldo, 2014.

GOETTERT, N. As tecnologias como ferramentas auxiliares na comunicação em Língua Portuguesa para usuários de Língua Brasileira de Sinais. In: CORRÊA, Y; CRUZ, C.R (Orgs.) Língua Brasileira de Sinais e tecnologias digitais. Porto Alegre: Penso, 2019, p. 125-142.

HANSEN, P. Adaptações de um modelo de ensino à distância para pessoas com deficiência. Dissertação (Mestrado em engenharia de produção) - Universidade Federal de Santa Catarina, 2003. 
KENSKI, V. M. O papel do professor na sociedade digital. In: CASTRO, A. D.; CARVALHO, A. M. P. (Org.). Ensinar a ensinar: didática para a escola fundamental e média. São Paulo: Pioneira Thomson Learning, 2001.

KUBASKI, C; MORAES, V. P; O Bilinguismo como proposta educacional para crianças surdas. IX Congresso nacional de educação - EDUCERE; III Encontro sul brasileiro de psicopedagogia; PUCPR, 2009.

LÉVY, P. A inteligência coletiva. São Paulo: Loyola, 1998.

LÉVY, P. O que é o Virtual? Tradução de Paulo Neves. São Paulo: Editora 34, 2011.

MARCUSCHI, L. A. Gêneros textuais emergentes no contexto da tecnologia digital. In: MARCUSCHI, L. A; XAVIER, A. C. (Orgs.). Hipertexto e gêneros digitais. Rio de Janeiro: Lucerna, 2004.

NOGUEIRA, A. S. Práticas de letramento multimodais em ambiente digital: uma possibilidade para repensar a educação de surdos. Revista Intercâmbio, Montes Claros, v. XXVIII, p. 19-45, 2014.

NOGUEIRA, A. S. O surdo não ouve, mas tem olho vivo - a leitura de imagens por alunos surdos em tempos de práticas multimodais. 2015. 307f. Tese de Doutorado em Linguística Aplicada - Universidade Estadual de Campinas, Campinas. 2015.

OLIVEIRA, M. A. N. Educação a Distância como estratégia para a educação permanente: possibilidades e desafios. Brasília: Revista Brasileira de Enfermagem, $\mathrm{n}$. 60, v. 5, p. 585-589, set-out, 2007.

SAMPAIO, I. S.; SANTOS, A. A. Leitura e redação entre universitários: avaliação de um programa de intervenção. Psicologia em Estudo, Maringá. 2002.

SANTOS, J. F. S. S. Avaliação do Ensino a Distância. In: Revista Iberoamericana de Educación, n. 38/4, 2006.

SOARES, R. D. S. Educação Bilíngue de surdos: desafios para a formação de professores. Diss. Universidade de São Paulo, 2013.

TRIVIÑOS, A. N. S. Introdução à pesquisa em ciências sociais: a pesquisa qualitativa em educação. São Paulo: Atlas, 1987.

Recebido em 10 de março de 2020

Aprovado em 22 de Abril de 2020

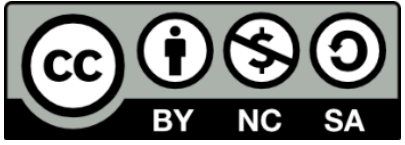

